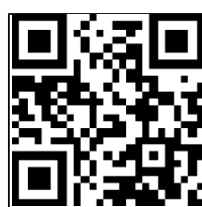

Editor's choice can to access mo free content

- Additional material is published online only. To view please visit the journal online (http://dx.doi.org/10.1136/ injuryprev-2015-041621).

Center for Injury Research and Policy, Johns Hopkins Bloomberg School of Public Health, Baltimore, Maryland, USA

Correspondence to Wendy Shields, Center for Injury Research and Policy, Johns Hopkins Bloomberg School of Public Health, 624 N. Broadway, Room 527B, Baltimore, MD 21205, USA; wshields@jhsph.edu

Received 24 March 2015 Revised 8 July 2015 Accepted 30 July 2015 Published Online First 20 August 2015

\title{
Structural housing elements associated with home injuries in children
}

\author{
Wendy Shields, Eileen McDonald, Shannon Frattaroli, David Bishai, Xia Ma, \\ Andrea Gielen
}

\section{ABSTRACT \\ Objective To quantify unintentional injuries associated with housing elements among children less than \\ 18 years old treated in US hospital emergency departments.}

Methods The National Electronic Injury Surveillance System (NEISS) coding manual was reviewed, and all product codes that identified products permanently affixed to a home (housing elements) were identified. A query of the 2008 NEISS data for children under 18 determined the numbers of cases by severity code for each identified housing element. Housing elements were then tabulated by the number of cases for each severity code. The top 10 cases by severity code, (1) hospitalised or (2) treated in emergency departments, were included in a case review. Ten per cent of all cases or a minimum of 100 cases were randomly selected for review for each of the identified housing elements to assess if the case description could inform prevention efforts.

Results Twelve housing elements (bathtub, cabinet, carpet, ceiling/wall, counter, door, fence, floor, nail, porch, stairs and window) were identified as the leading causes of injuries resulting in hospitalisations or emergency department visits. A list of potential interventions was generated based on the review of the case histories. Suggested changes for NEISS coding are also offered to enhance future prevention research.

Conclusions NEISS is a valuable tool to identify home injury risks and inform design decisions for housing elements. Improved understanding of housing elements associated with injuries has the potential to enhance home inspection forms. However, interpretation of NEISS results is limited by lack of clarity about how the housing element was involved in the injury event.

\section{INTRODUCTION}

Home injuries are common, accounting for one-third of all unintentional injuries in the USA. In addition, the home is the second most common place for fatal injuries. ${ }^{1}$ Children, in particular, experience injuries in their home environments at high rates. ${ }^{1}{ }^{2}$ According to the report, The State of Home Safety in America, almost 2100 children younger than 15 years of age die every year from injuries in and around the home; for every death, there are almost 1600 non-fatal home injuries. ${ }^{2}$ CrossMark Home injuries to children is a global health issue. In the UK, approximately 40000 emergency hospital admissions among children under 5 years of age are reported annually. ${ }^{3}$ In 2005 , WHO and Unicef issued a call for a greater global effort to prevent child injury, culminating in the World report on child injury prevention, which sought to bring awareness about the global problem of child injuries and to provide recommendations that all countries can follow to reduce child injuries effectively. $^{4}$

While it is well accepted that how an individual interacts with his environment can be causally related to his injury risk and that safety products such as stair gates can mitigate risk, there is little quantitative evidence as to the specific built environment features of the home itself that can contribute to injuries in children. To date, injury prevention home inspection tools have focused more on the presence of countermeasures such as smoke alarms, stair gates and carbon monoxide alarms rather than on housing elements and their association with injuries. ${ }^{5}$ Previous work has evaluated the effectiveness of efforts to reduce home injuries primarily from injury countermeasures such as smoke alarms and antiscald devices. The interventions focused on modifying environmental home hazards, such as fitting locks on cupboards, installing stair gates, improving lighting and removing tripping hazards, have shown insufficient evidence that they significantly reduce home injury. ${ }^{6}$ Kendrick et $a l^{7}$ found successes in home safety interventions focusing on safe hot water temperature, working smoke alarms, fire escape plans, fitted stair gates, socket covers and poison and medicine storage. Sharfstein and colleagues found housing characteristics, including heating adequacy, presence of rodents and holes in walls, to be independent predictors of child health status, but this outcome did not include a measure of injury. ${ }^{8} \mathrm{~A}$ few other studies, including our own earlier work, have demonstrated that living in poor quality housing conditions in poor neighbourhoods is associated with increased risk of home injury for children, and can also be significant barriers to using home safety products. $^{9-12}$ Modifying the home environment could have a significant impact on home injury outcomes. Researchers in New Zealand found that home injuries were potentially related to a structural aspect of the home environment. ${ }^{13}$ To wit, Keall et al ${ }^{14}$ successfully targeted fall injuries through a successful home modification programme (eg, handrails, repairs to steps, non-slip modifications, lighting, etc), resulting in a significant decrease in falls.

The purpose of this paper is to add to this small body of literature data on specific built environment features of homes that are associated with children's injury using the National Electronic Injury Surveillance System (NEISS). NEISS is a publicly available database overseen by the US Consumer Product Safety Commission (CPSC). 
NEISS has been used to explore injuries from a wide variety of products, including those from recreational activities including mountain biking, ${ }^{15}$ unicycles ${ }^{16}$ and water tubing ${ }^{17}$; occupational injuries from ladders ${ }^{18}$ and nail guns, ${ }^{19}$ and home injuries including hot tubs ${ }^{20}$ and bunk beds. ${ }^{21}$ Although focused on consumer product-related injuries, NEISS also captures information about injuries more broadly, and thus, can help identify hazardous conditions in the home. ${ }^{22}$ We first present frequencies of the leading types of structural housing elements associated with child injury, followed by a summary of the narrative description of these injuries. We conclude with recommendations that could be implemented either during home construction or as a part of home inspections to prevent the identified injuries. Finally, we make suggestions about enhancements to NEISS, which would make it more useful for practitioners.

\section{METHODS}

The NEISS-All Injury Program (NEISS-AIP) uses data from a nationally representative sample of 62 hospitals in the USA. NEISS consists of a probability sample of hospital emergency departments (EDs) in the USA and its territories that is used to produce national estimates of the number of consumer product-related injuries treated in hospital EDs. ${ }^{23}$ (For additional details on the design and implementation of NEISS, see http://www.cpsc.gov/neiss/2001d011-6b6.pdf.) We used NEISS 2008-2012 data for quantitative analysis. To define eligible injuries, we first reviewed the NEISS coding manual (http:// www.cpsc.gov/neiss/completemanual.pdf) to determine codes that were related to the home environment. Consistent with the purpose of our analysis, we defined eligible injuries as those associated with 'structural housing elements that were attached to the home'. Examples of attached items included floors, windows, cabinets, bathtubs, etc. Examples of excluded unattached items are curtains and televisions. In all, 26 codes reflecting attached structural housing elements were selected for analysis. We queried the NEISS-AIP database for 2008, and identified the top 10 structural housing elements associated with emergency room visits and the top 10 structural housing elements associated with hospitalisations for children aged 1 month to 18 years. We then selected the 12 structural housing elements, which represented the combined top 10 lists for both emergency room visits and hospitalisations. We then queried the

Table 1 Housing-related injuries identified from NEISS-AIP 2008

\begin{tabular}{llll}
\hline $\begin{array}{l}\text { Housing } \\
\text { element }\end{array}$ & $\begin{array}{l}\text { ED visits, NEISS } \\
\text { sample }\end{array}$ & $\begin{array}{l}\text { ED visits, national } \\
\text { estimate }\end{array}$ & $\begin{array}{l}\text { ED visits, national } \\
\text { estimate rate } \\
\text { (per 100 000) }\end{array}$ \\
\hline 1. Floor & 6886 & 206668 & 67.96 \\
2. Stair & 4983 & 150015 & 49.33 \\
3. Door & 3033 & 92228 & 30.33 \\
4. Ceiling & 2424 & 77195 & 25.39 \\
5. Bathtub & 1595 & 49789 & 16.37 \\
6. Cabinet & 1149 & 36988 & 12.16 \\
7. Window & 916 & 27670 & 9.10 \\
8. Nail & 892 & 31243 & 10.27 \\
9. Carpet & 812 & 19600 & 6.45 \\
10. Porch & 746 & 24644 & 8.10 \\
11. Fence & 687 & 21715 & 7.14 \\
12. Counter & 670 & 19282 & 6.34 \\
\hline
\end{tabular}

ED, emergency department; NEISS-AIP, National Electronic Injury Surveillance System-All Injury Program.
2008 NEISS-AIP for each of the identified structural housing elements for children aged 1 month to 18 years; the query generated a sample for the 62 NEISS hospitals as well as a national estimate. The sample file included race, age, gender, injury disposition and a case narrative for each record. A random sample of narratives (approximately 10\% of total number of injuries or at a minimum $\mathrm{n}=100$ if $10 \%$ was less than $\mathrm{n}=100$ ) were selected for review. The study team conducted a review of these narratives to identify potential preventive measures in light of currently available countermeasures and with attention to the time and cost of the proposed modification. We distinguished primary prevention solutions (eg, antislip coating in tubs and floors, locking devices on windows) that need to be incorporated during construction of new homes from secondary solutions (ie, grab bars, removal of protruding nails) that could be addressed during home inspections. Examination and discussion of the case narratives was used to identify preventive measures. The Institutional Review Board of the Johns Hopkins Bloomberg School of Public Health approved this study.

\section{RESULTS}

\section{Housing-related injuries identified}

The twelve housing elements associated with the highest number of ED visits or hospitalisations from the NEISS dataset are shown in table 1 . The NEISS sample and national estimates of ED visits for each of these structural housing elements are also displayed in table 1 . The NEISS estimate of ED visits associated with the identified housing elements ranged from a high of 206668 (67.96 per 100000 annually) for floors, to a low of 19282 (6.34 per 100000 annually) for injuries associated with counters. The analysis identified well-documented injury risks, such as stairs, with an estimated 150015 (49.33 per 100000 annually) ED visits and bathtubs with 49789 (16.37 per 100000 annually) estimated ED visits. Our analysis also identified less obvious injury risks such as the estimated 77195 (25.39 per 100000 annually) ED visits associated with ceilings and 31243 (10.27 per 100000 annually) injuries associated with protruding nails.

\section{Demographics}

As displayed in table 2, males account for the majority of injuries for all housing elements; the percentage was highest for fences where males accounted for $67 \%$ of injuries compared

Table 2 Demographics and disposition of injuries caused by the 12 housing elements

\begin{tabular}{lllrr}
\hline $\begin{array}{l}\text { Housing } \\
\text { element }\end{array}$ & $\begin{array}{l}\text { Mean age } \\
\text { (N=months) }\end{array}$ & \multicolumn{1}{l}{$\begin{array}{l}\text { Sex=male } \\
\mathbf{N}(\%)\end{array}$} & $\begin{array}{l}\text { Race=white } \\
\mathbf{N}(\%)\end{array}$ & $\begin{array}{l}\text { Disposition=treated } \\
\text { and released } \\
\mathbf{N}(\%)\end{array}$ \\
\hline Bathtub & 72.7 & $858(53.79)$ & $675(42.32)$ & $1523(95.49)$ \\
Cabinet & 62.2 & $704(61.27)$ & $515(44.82)$ & $1114(96.95)$ \\
Carpet & 47.1 & $452(55.67)$ & $299(26.82)$ & $772(95.07)$ \\
Ceiling & 93.5 & $1530(62.12)$ & $1001(41.30)$ & $2389(98.56)$ \\
Counter & 57.0 & $393(58.66)$ & $308(45.97)$ & $637(95.07)$ \\
Door & 74.9 & $1655(54.57)$ & $1147(37.82)$ & $2997(98.15)$ \\
Fence & 108.7 & $460(67.45)$ & $272(39.88)$ & $644(94.43)$ \\
Floor & 50.2 & $3682(53.47)$ & $2551(37.05)$ & $6480(96.10)$ \\
Nail & 102.3 & $564(63.23)$ & $373(41.82)$ & $864(96.86)$ \\
Porch & 85.3 & $429(57.51)$ & $334(44.77)$ & $690(92.49)$ \\
Stair & 85.2 & $2535(50.87)$ & $1992(39.98)$ & $4793(96.19)$ \\
Window & 105.5 & $582(63.54)$ & $350(38.21)$ & $816(89.08)$ \\
\hline
\end{tabular}


with only $51 \%$ of injuries on stairs. The vast majority of injuries resulted in children being treated and released-more than $90 \%$ for every element except injuries associated with windows, which was $89 \%$. The lowest mean age for children was 47.1 months for injuries associated with carpets, while the highest mean ages were associated with fences (108.7), windows (105.5) and nails (102.3).

\section{Case narratives and potential solutions}

Case narratives providing more details about injury events were reviewed and organised by each of the 12 housing elements. Examples of narratives that were typical and provided the range of experiences were selected for display in online supplementary table S1. Many injuries resulted from slips, trips and falls, particularly those associated with stairs, carpets and bathtubs. Nail injuries generally resulted in lacerations and puncture wounds. Door injuries resulted from doors being closed on fingers to doors falling on children. The scenarios include varying amounts of information, and there is no consistent structure to the level of detail provided. In some cases, there is an interaction of the child with the housing element after some risky behaviour (eg, child running or jumping); in other cases, the housing element seemed to malfunction in the absence of any specific risky behaviour by the child (eg, shower door fell); and finally, in some cases, the housing element seemed to have been used appropriately, and the child was injured in the absence of any specific risky behaviour (eg, slipped in tub).

After reviewing each narrative, the authors identified a number of potential countermeasures to prevent injuries associated with each housing element. For example, bathtub narratives describe many examples of slips and falls generating a countermeasure recommendation of installing tubs with slip-resistant surfaces. The door case narratives revealed serious injuries to fingers, including amputation, which could be minimised by installing doorstops as a countermeasure.

\section{DISCUSSION}

The NEISS database is a tremendous national resource, which has demonstrated real-world utility since its inception. The examination and presentation of NEISS data have led to product recalls (eg, lawn darts, high-powered magnet sets), ${ }^{24} 25$ creation of voluntary standards (eg, window blind cords) ${ }^{26}$ and even awareness of injury sources, leading to the development of new, safer equipment (eg, tractor rollover protective structures). ${ }^{27}$ It has had a significant impact in recreational, household and occupational products, which affect people daily. Injury surveillance systems are employed in other countries, though none have been as extensively used for reporting in the peer-reviewed literature as the NEISS. A review of The Canadian Hospitals Injury Reporting and Prevention Program data has shown great variance of sensitivity and systematic errors in data capture. ${ }^{28}$ The National Injury Surveillance Unit of Australia has an acknowledged shortcoming in that it lacks a source of national quantitative data suitable for monitoring consumer product safety. ${ }^{29}$ The Home and Leisure Accident Surveillance System of the UK was discontinued in $2003 .{ }^{30}$ This manuscript reports on our usage of the NEISS database to explore the burden of unintentional injuries associated with housing elements among children less than 18 years old treated in US hospital EDs.

Demographically, our results are in line with other national samples with males experiencing more injuries than females. ${ }^{31}$ The great majority of injured patients for each of the housing elements explored were treated and released from the ED, which is also consistent with the reporting on injuries broadly. ${ }^{31}$ The NEISS data system provided an opportunity to identify housing elements associated with home injuries and to suggest countermeasures that could be used to prevent them either at the time of home construction or during home inspections (eg, for resale, mortgages or as part of home visiting programmes). Previous research using the NEISS data system has reported products with substantially lower yearly estimates than structural housing elements. For example, Thompson $e t a l^{32}$ reported on an estimated 64657 (3232 per year) inflatable bounce house injuries over a 20 -year period ending in 2010. D'Souza et $a l^{21}$ reported on an estimated 572580 (35 786 injuries annually) bunk bed injuries over a 16-year period ending in 2005. Injuries associated with ladders were also reported by D'Souza with an estimated 2177888 injuries in the USA over a 16-year period ending in $2005 .^{33}$ D'Souza's ladder work reported an average yearly estimate of 136118 , ranking it below the highest two housing elements we identified in our analysis: floors at 206668 and stairs at 150015.

When case narratives provided sufficient detail about the circumstances surrounding the injury, we could offer recommendations for prevention such as the use of antislip surfaces in the bathroom or the removal of protruding nails. In other cases, sufficient detail was not offered in the narrative to truly understand housing element's contribution to the injury. Our original intent was to code each injury as being associated with the condition or the housing element. For example, if an injury associated with a door was due to a defect in the door as opposed to a child running into the door but this was not possible because of the lack of necessary detail in the case narratives. It would be extremely helpful if all individuals from hospital administrators to intake clerks to clinical staff as well as NEISS coders were trained to note as specifically as possible the circumstances surrounding an injury event and to extract as much detail as possible so that the precipitating events and causation could be better elucidated and understood from the NEISS narratives. ${ }^{34}$ It would also be helpful if the NEISS narrative field allowed for more text to be entered; currently, only 141 characters are permitted for the narrative details, which is supposed to include a description of what the victim was doing when the injury occurred, the product involved, location and verbatim quotes. The character limit may not allow enough space to detail the condition of the products. We observed several instances of the narrative text being truncated mid-description, and think that, at least in some cases, time allows for coders to record a description longer than 141 characters. It may be prudent to pilot these suggestions with a small sample to estimate the time and cost burden as well as to gauge the benefit of the added information. It may also be possible to consider these changes to the data system when the system is next upgraded. Additionally, it would also be useful to validate the conclusions we draw about the role of the housing element itself by follow-back interviews with parents or the child when old enough. Our suggested enhancements to NEISS are not novel. As early as 1997, the Government Accountability Office produced a report entitled 'Consumer Product Safety Commission: Better data needed to help identify and analyze potential hazards', which called attention to NEISS's inability to generate estimates for anything smaller than a national sample, limiting its utility for state and regional estimates and making interstate comparisons impossible. The same report also noted that NEISS lacked the detail necessary to assess causality, that is, whether the product in question caused the injury or merely was involved with the injury. It, additionally, noted that NEISS did not contain E 
codes, which briefly described the circumstances of the injury, and suggested that such detail would be helpful in understanding the injuries reported by NEISS. ${ }^{35}$ More recent work has explored the utility of using NEISS narrative texts to identify exposure information in case-control studies. ${ }^{36}$ Graves et $a l^{36}$ found the narrative useful, but noted that the utility was limited to the information, which was asked and recorded throughout the clinical encounter.

Using NEISS data to inform the relationship between housing elements and injury risks presents several limitations. The NEISS database does not capture visits of patients who seek treatment at non-ED locations such as their primary care provider or an urgent care centre; therefore, treatment at urgent and primary care centres is excluded from the national estimates. Information regarding follow-up care is not available in NEISS, preventing analysis beyond the initial ED visit. Details offered in the case narratives were frequently insufficient in understanding the relationship between the injury event and the precipitating events and housing element condition. Additionally, case narratives of child injuries do not routinely include information about whether an adult witnessed the injury event or if an adult was supervising the child at the time of the event. This lack of detail prevents a full understanding of the cause of injury, and therefore, limits our ability to fully understand which preventive measures could reduce injuries. The addition of standardised fields to collect detail about condition of product, precipitating events and adult supervision could greatly enhance the utility of the NEISS dataset. Again, a pilot trial of a system of standardised fields would be necessary to estimate the time and cost burden. Many of the narrative texts we examined included some elements of the standardised fields we are suggesting indicating that in some cases the detail is available. However, the information was not recorded systematically or routinely, making the analysis and synthesis less feasible.

Our recommendations are complimentary to those put forward in the 2008 World report on child injury prevention, which calls specifically for enhanced quality and quantity of data for child injury prevention. While NEISS is already responsive to several recommendations made by the World report on child injury prevention, further enhancements to the system will improve on these activities. With more details on causes of injury, NEISS could be used to help implement specific actions to prevent and control child injuries. Further, greater detail on the cause of injury and causation through the narratives will enhance the quality and quantity of data for child injury prevention. ${ }^{4}$

Studying NEISS revealed that structural housing elements vary in their propensity to injure. Structural housing elements are very common source of injury. NEISS narratives are a valuable tool to identify potential countermeasures-both primary and secondary-for injury prevention. This analysis can be used as a foundation for evidence-based programmes to inspect housing structures to make them safer. Individuals conducting home inspections or building new homes could benefit from the prevention measures, which were identified in this analysis. Additionally, we hope that the injury community, broadly, and the CPSC, specifically, consider modifications to NEISS, particularly the narratives, to allow for the capture of greater details that could be used to establish a more comprehensive understanding of the involvement of a product in causing or contributing to an injury as well as the precipitating and contributing factors surrounding injury events. Such detail would allow for the development of more robust injury prevention initiatives.

\section{What is already known on the subject?}

Home injuries are common, accounting for one-third of unintentional injuries in the USA. Little information is available describing the involvement of specific housing elements as risk factors for home injuries to children and adolescents.

\section{What this study adds?}

Twelve housing elements were identified as being most commonly associated with emergency department visits among children and adolescents in the USA. Potential countermeasures were identified that individuals can use in designing new homes or inspecting existing homes.

Acknowledgements The authors acknowledge the following individuals who contributed to this project: Sarah Cha, Safiyya Dharssi and Trevor Pascoe at Johns Hopkins Bloomberg School of Public Health.

Contributors WS was the lead on this manuscript. She oversaw the data coding, analysis and manuscript preparation. XM conducted the data analysis. AG, EM, SF and DB contributed towards developing the coding plan and revising the manuscript.

Funding This research was funded by a grant to Johns Hopkins Bloomberg School of Public Health from the CDC (Grant No. 5RO1 HD042777-03).

Competing interests None declared.

Provenance and peer review Not commissioned; externally peer reviewed.

Data sharing statement The data from this analysis are publicly available from the Consumer Product Safety Commission's National Electronic Injury Surveillance System.

\section{REFERENCES}

1 Runyan CW, Casteel C, Perkis D, et al. Unintentional injuries in the home in the United States part I: mortality. Am J Prev Med 2005;28:73-9.

2 Finkelstein EA, Corso PS, Miller TR. The incidence and economic burden of injuries in the United States. New York: Oxford University Press, 2006:161.

3 Public Health England. Reducing unintentional injuries in and around the home among children under five years. London: Public Health England, 2014.

4 Peden M, Oyebite K, Ozanne-Smith J, et al. World report on child injury prevention. Geneva, Switzerland: World Health Organization, 2008.

5 Phelan KJ, Koury J, Xu Y, et al. Validation of a home injury survey. Inj Prev 2009;15:300-6.

6 Turner S, Arthur G, Lyons RA, et al. Modification of the home environment for the reduction of injuries. Cochrane Database Syst Rev 2011;(2):CD003600.

7 Kendrick D, Young B, Mason-Jones AJ, et al. Home safety education and provision of safety equipment for injury prevention. Cochrane Database Syst Rev 2012;9: CD005014.

8 Sharfstein J, Sandel M, Kahn R, et al. Is child health at risk while families wait for housing vouchers? Am J Public Health 2001;91:1191-2.

9 Gielen AC, Wilson MEH, Faden R, et al. In-home injury prevention practices for infants and toddlers: the role of parental beliefs, barriers, and housing quality. Heal Educ Quart 1995;22:85-95.

10 Cubbin C, Smith GS. Socioeconomic inequalities in injury: critical issues in design and analysis. Ann Rev Publ Health 2002;23:349-75.

11 LeBlanc JC, Pless B, King JW, et al. Home safety measures and the risk of unintentional injury among young children: a multicentre case-control study. Canadian Med Assoc J 2006;175:883-7.

12 Kendrick D, Mulvaney C, Burton P, et al. Relationship between child, family, and neighborhood characteristics and childhood injury: a cohort study. Soc Sci Med 2005:61:1905-15.

13 Keall MD, Howden-Chapman P, Baker MG, et al. Formulating a programme of repairs to structural home injury hazards in New Zealand. Accid Anal Prev 2013;57:124-30.

14 Keall MD, Pierse N, Howden-Chapman P, et al. Home modifications to reduce injuries from falls in the home injury prevention intervention (HIPI) study: a clusterrandomised controlled trial. Lancet 2014;385:231-8. 
15 Nelson NG, McKenzie LB. Mountain biking-related injuries treated in emergency departments in the United States, 1994-2007. Am J Sports Med 2011;39:404-9.

16 Wang ML. Unicycle injuries in the United States. J Emerg Med 2013;44:502-7.

17 Heinsimer KR, Nelson NG, Roberts KJ, et al. Water tubing-related injuries treated in US emergency departments, 1991-2009. J Phys Act Health 2013;10:151-9.

18 Socias CM, Chaumont Menéndez CK, Collins JW, et al. Centers for disease control and prevention (CDC). MMWR Morb Mortal Wkly Rep 2014;9:341-6. Erratum in: MMWR Morb Mortal Wkly Rep 2014;9:416.

19 Lipscomb HJ, Schoenfisch AL. Nail gun injuries treated in U.S emergency departments, 2006-2011: Not just a worker safety issue. Am J Ind Med 2015:58:880-5.

20 Alhajj M, Nelson NG, McKenzie LB. Hot tub, whirlpool, and spa-related injuries in the U.S., 1990-2007. Am J Prev Med 2009;37:531-6.

21 D'Souza AL, Smith GA, McKenzie LB. Bunk bed-related injuries among children and adolescents treated in emergency departments in the United States, 1990-2005. Pediatrics 2008;121:e1696-702.

22 Mao SJ, McKenzie LB, Xiang $H$, et al. Injuries associated with bathtubs and showers among children in the United States. Pediatrics 2009;124:541-7.

23 Schroeder T, Ault K. The NEISS Sample (Design and Implementation) 1997 to Present. U.S. Consumer Product Safety Commission. 2001. http://www.cpsc.gov/ neiss/2001d011-6b6.pdf (accessed 1 Aug 2010).

24 U.S. Consumer Product Safety Commission. Following Recent Injury CPSC Reissues Warning: Lawn Darts Are Banned and Should Be Destroyed. 1997. http://www.cpsc. gov/en/Newsroom/News-Releases/1997/Following-Recent-Injury-CPSC-ReissuesWarning-Lawn-Darts-Are-Banned-and-Should-Be-Destroyed/ (accessed date $7 \mathrm{Jul}$ 2015).

25 U.S. Consumer Product Safety Commission. Buckyballs and Buckycubes HighPowered Magnet Sets Recalled Due to Ingestion Hazard; Craig Zucker To Fund A
Recall Trust, Settles With CPSC. 2014. http://www.cpsc.gov/en/Newsroom/NewsReleases/2014/Buckyballs-and-Buckycubes-High-Powered-Magnet-Sets-Recalled/ (accessed date 7 Jul 2015).

26 U.S. Consumer Product Safety Commission. Window Bling Cords Voluntary Standards Activities. 2013. http://www.cpsc.gov/en/Regulations-Laws-Standards/ Voluntary-Standards/Window-Blind-Cords/ (accessed 7 Jul 2015).

27 Reynolds S, Groves W. Effectiveness of roll-over protective structures in reducing farm tractor fatalities. Am J Prev Med 2000;18(4 Suppl):63-9.

28 Hopkins R. Farm equipment injuries in a rural county, 1980 through 1985: the emergency department as a source of data for prevention. Ann Emerg Med 1989;18:758-62.

29 Harrison J. Australian injury surveillance data standards. Ann Emerg Med 2010. http://www.cdc.gov/nchs/data/ice/ice95v2/c04.pdf

30 The Royal Society for the Prevention of Accidents. HASS and LASS Home \& Leisure Accident Surveillance System. http://www.hassandlass.org.ukJ (accessed date 7 Jul 2015).

31 http://www.cdc.gov/injury/wisqars/nonfatal.html (accessed date 7 Jul 2015).

32 Thompson MC, Chounthirath T, Xiang H, et al. Pediatric inflatable bouncer-related injuries in the United States, 1990-2010. Pediatrics 2012;130:1076-83.

33 D'Souza AL, Smith GA, Trifiletti LB. Ladder-related injuries treated in emergency departments in the United States, 1990-2005. Am J Prev Med 2007;32:413-18.

34 U.S. Consumer Product Safety Commission. NEISS Coding Manual. 1982. https:// www.cpsc.gov//Global/Neiss_prod/completemanual.pdf

35 U.S. General Accounting Office. Consumer Product Safety Commission: better data needed to help identify and analyze potential hazards (HEHS-97-147). Washington DC: General Accounting Office, 1997 [7 July 2015]. http://www.gao.gov/products/ HEHS-97-147

36 Graves JM, Whitehill JM, Hagel BE, et al. Making the most of injury surveillance data: using narrative text to identify exposure information in case-control studies. Injury 2015;46:891-7.

\section{Compensation paid by UK council}

In the past 2 years Oxfordshire County Council paid over $f 700000$ in compensation to people who suffered injuries due to pot-holes, road or footpath defects, icy pavements or uneven paving. One person made a claim of $£ 65734$ after a brain injury due to uneven paving. The Taxpayers' Alliance found the county council spent $£ 142282$ on pot-hole compensation claims since 2013. 